\title{
Correction to: Effect of the Magnetic Pole Arrangement on the Surface Roughness of STS 304 by Magnetic Abrasive Machining
}

\author{
Cheng Yin ${ }^{1} \cdot$ Juei-Feng Tu ${ }^{2} \cdot$ Jun Ho Lee ${ }^{3} \cdot$ Gyun Eui Yang ${ }^{1} \cdot$ Sang Don Mun ${ }^{3}$
}

Published online: 22 May 2019

c) Korean Society for Precision Engineering 2019

\section{Correction to: \\ INTERNATIONAL JOURNAL OF PRECISION ENGINEERING AND MANUFACTURING Vol. 15, No. 7, pp. 1275-1281 https://doi.org/10.1007/s12541-014-0467-x}

One of the authors of this article wishes to change his name given based on Korean pronunciation to a Chinese version. Accordingly, the author name "Sung Yoon" should instead appear as "Cheng Yin".

Publisher's Note Springer Nature remains neutral with regard to jurisdictional claims in published maps and institutional affiliations.

The original article can be found online at https://doi.org/10.1007/ s12541-014-0467-x.

Sang Don Mun

msd@jbnu.ac.kr

1 Division of Mechanical Engineering, Chonbuk National University, 664-14, Duckjin-dong, Duckjin-gu, Jeonju, Seoul 561-756, South Korea

2 Department of Mechanical and Aerospace Engineering, North Carolina State University, 911 Oval Drive,

Raleigh 27695-7910, USA

3 Division of Mechanical Design Engineering, Chonbuk National University, 664-14, Duckjin-dong, Duckjin-gu, Jeonju, Seoul 561-756, South Korea 